\title{
PREVALENCE OF LOW BACK PAIN AMONG BANKERS OF LAHORE, PAKISTAN
}

\section{Sana Tauqeer ${ }^{\boxplus 凶}$, Fareeha Amjad', Ashfaq Ahmed', Syed Amir Gillani'}

\begin{abstract}
OBJECTIVE: To find out the prevalence of low back pain among bankers of Lahore, Pakistan.

METHODS: This cross-sectional survey was conducted from April-September 2017 on 164 bankers with age group of 22-58 years working in different government and private banks of Lahore, Pakistan. Participants with any accident, fracture and tumor were excluded. Japanese Orthopedic Association Back Pain Evaluation Questionnaire was used. The bankers were interviewed and asked to fill in the questionnaires. Statistical Analysis was done by using SPSS version 21 .
\end{abstract}

RESULTS: Total 164 subjects were included in the study with 1 I $3(68.90 \%)$ males and $5 \mathrm{I}(31.10 \%)$ females. Mean age of respondents was $30.46 \pm 6.57$ years. The prevalence of low back pain in bankers was $52.4 \%(n=86 / 164)$, more prevalent in males $(n=46 ; 53.5 \%)$ as compared to females $(n=40$; $46.5 \%)$. Study revealed that $84(97.7 \%)$ respondents changed their posture, 61 (70.9\%) lied down more often than usual, 55 (64.0\%) refrained from bending, $5 \mathrm{I}(59.3 \%)$ faced difficulty in putting on socks, 49 (57.0\%) faced difficulty in standing from chair, 46 (53.5\%) went up the stairs slowly, 45 (52.3\%) could not sleep, $45(52.3 \%)$ asked help from others and 45 (52.3\%) walked only short distances.

CONCLUSIONS: The prevalence of low back pain is high among bankers, more among the men than women. It was found that due to low back pain, bankers were not able to do daily life activities.

KEY WORDS: Low Back Pain (MeSH); Posture (MeSH); Musculoskeletal Pain (MeSH); Prevalence (MeSH); Bankers (Non-MeSH).

THIS ARTICLE MAY BE CITED AS: Tauqeer S, Amjad F, Ahmed A, Gillani SA. Prevalence of low back pain among bankers of Lahore, Pakistan. Khyber Med Univ J 2018;10(2):101-104.

\section{INTRODUCTION}

ow back pain (LBP) is a major workrelated health problem. In musculoskeletal health care low back problems are one of the most expensive situations.' Among all musculoskeletal problems low back pain is most common. ${ }^{2}$ Along with low back pain the musculoskeletal disability is also one of the most important cause around the world. ${ }^{3}$ Low back pain is further classified into three types acute, subacute and chronic low back pain. Low back pain that continues for less than six weeks is called acute low back pain. Low back pain that occurs between the time period of six weeks and three months is called subacute low back pain and the back pain that goes on for more than three months is known as chronic low back pain. ${ }^{4}$ Incorrect sitting posture is a cause of pain at lower back. Cervical spine pain or neck pain can be caused by incorrect sitting posture. ${ }^{5}$ More than $80 \%$ of population will experience an occurrence of low back pain at some point in life.

Banking has a great importance in any nation around the globe. It has helped in emerging the dynamic parts of the economy and guides a new dawn of development. Banks are one of the most important parts of any country. In this modern time money and its
$1^{凶}$ University Institute of Physical Therapy, The University of Lahore. Email: sanakhan2333444@gmail.com

Date Submitted: October 09, 2017

Date Revised: June 07,2018

Date Accepted: June 09,2018

necessity is very important. A developed financial system of the country can ensure scope for attaining economic development. A modern bank provides valuable services to a country. To attain development there should be a good developed financial system to support not only economic but also the society. So, a modern bank plays a vital role in socioeconomic matters of the country.

In the banking zone bank staff uses the computer continuously during the working hours for many purposes such as data collection, dealing and programming etc. So, they are open to high risk of developing musculoskeletal disorders. Workings in banks require movements such as more flexion of the neck, back, arms, hands and fingers. These factors are associated with increased risk of pain and musculoskeletal disorders. ${ }^{8}$ Musculoskeletal disorders mainly upper limbs problems and back problems are mostly present among bank staff.' Previous studies on bank staff conducted on international levels has shown high occurrence of back pain. Prevalence was ranging between $60 \%{ }^{10}$ to $80 \%$." According to a study during last 12 months $40.4 \%$ respondents were suffering from low back pain. Mostly bankers had highest occurrence of upper back pain in both males and females. About $62 \%$ females were having lower back pain. In this study females were having more pain than males. ${ }^{12}$ Occurrence rate was $64.8 \%$. Pain in upper back was $61.7 \%$, pain in neck was $47.4 \%$ and pain in shoulder was $37.4 \%$. $^{13}$ There are many factors that can trigger low back pain in bankers some of them are there sitting posture, job pressure, psychosocial stress, job tenure, and working hours. As there are limited studies done in our setup, we conducted this study to find out the prevalence of low back pain among bankers of Lahore, Pakistan. 
TABLE I: FREQUENCY DISTRIBUTION OF BASELINE CHARACTERISTICS $(n=86)$

\begin{tabular}{|c|c|c|}
\hline \multirow{2}{*}{ Characteristics } & \multicolumn{2}{|c|}{ Frequency (Percentage) } \\
\hline & Yes & No \\
\hline Change posture & $84(97.7 \%)$ & $2(2.3 \%)$ \\
\hline Lie down more & $61(70.9 \%)$ & $25(29.1 \%)$ \\
\hline Refrain from bending & $55(64.0 \%)$ & $31(36.0 \%)$ \\
\hline Putting on socks is difficult & $5 \mathrm{I}(59.3 \%)$ & $35(40.7 \%)$ \\
\hline Difficulty in standing from chair & $49(57.0 \%)$ & $37(43.0 \%)$ \\
\hline Go upstairs slowly & $46(53.5 \%)$ & $40(46.5 \%)$ \\
\hline Cannot sleep & $45(52.3 \%)$ & $4 \mathrm{I}(47.7 \%)$ \\
\hline Ask help & $45(52.33 \%)$ & $41(47.67 \%)$ \\
\hline Walk short distances & $45(52.3 \%)$ & $4 \mathrm{I}(47.7 \%)$ \\
\hline Back is always aching & $44(51.2 \%)$ & $42(48.8 \%)$ \\
\hline Turning over bed is difficult & $44(51.2 \%)$ & $42(48.8 \%)$ \\
\hline Get irritated & $39(45.3 \%)$ & $47(54.7 \%)$ \\
\hline Stay seated & $39(45.3 \%)$ & $47(54.7 \%)$ \\
\hline Do not do house work & $37(43.0 \%)$ & $49(57.0 \%)$ \\
\hline
\end{tabular}

\section{METHODS}

In this cross-sectional study 164 bankers were conveniently included in the study during the time period of April 2017 to September 2017. Bankers between age group of 22 to 58 were selected and interviewed in this study because mostly bankers are from in age group. Questionnaires were distributed among bankers. Total 250 questionnaires were distributed among which 150 were given by hand and rest were sent through email 70 questionnaires were eliminated as they were not according to the including criteria (subjects between 22-58 years). Prevalence of low back pain and problems in daily life activities due to low back pain were recorded using Japanese Orthopedic Association Back Pain Evaluation Questionnaire. ${ }^{14}$

Sample size of this study was 164 that were calculated by using Epi tools sample size calculator software. Formula used for this purpose was $\mathrm{n}=$ $\left(Z^{2}\right.$ ? $P(I$ ? $\left.P)\right) / e^{2}$. Where $Z$ = value from standard normal distribution corresponding to desired confidence level $(Z=1.96$ for $95 \% \mathrm{Cl}$ ), $\mathrm{P}$ is expected true proportion, e is desired precision (half desired $\mathrm{Cl}$ width). Data was collected from bankers working in different banks of Lahore, Pakistan. Study was completed within 6 months after the approval of synopsis.

Bankers who were working in
(86/164). Low back pain was more prevalent in male bankers (46) as compared to female (40).

The results showed that $84(97.7 \%)$ respondents changed their posture, $6 \mathrm{I}$ (70.9\%) lied down more often than usual, $55(64.0 \%)$ refrained from bending, 5 I (59.3\%) faced difficulty in putting on socks, 49 (57.0\%) faced difficulty in standing from chair, 46 $(53.5 \%)$ went up the stairs slowly, 45 (52.3\%) could not sleep, 45 (52.3\%) asked help from others and 45 (52.3\%) walked only short distances (Table I).

\section{DISCUSSION}

This cross-sectional study was conducted to find out the prevalence of low back pain among bankers of Lahore, Pakistan. This study shows that low back pain was common in male than female. There were II3 (68.90\%) males and $5 \mathrm{I}$ (31.10\%) females. A survey was conducted in Kancheepuram district which determined the occurrence of musculoskeletal disorders and related disabilities amongst bank staff. They described annual occurrence of the musculoskeletal disorders was $33.8 \%$ while that of the related disability was $8.5 \%$. For both the disorders and related disabilities the occurrence of provincial musculoskeletal disorders was maximum in the lower back and earlier studies also stated same results with greater occurrence. ${ }^{13,15}$ The present study showed that prevalence of low back pain among bank workers of Lahore, Pakistan is $52.44 \%$ whereas results of a study conducted among bank staff of Yazd city stated that prevalence of low back pain is $18.6 \%$. $^{16}$ Another research was conducted in Tamil Nadu, India to find out occurrence of musculoskeletal disorders among bank staff stated that prevalence of low back pain was $51.8 \%{ }^{17}$

Lower back, upper back, neck, shoulder, wrist and hand were the regions where most of the regional musculoskeletal disorders occur. ${ }^{11,13,18}$ The present study described that low back pain is most common. Present study also stated that bad posture is main factor that causes low back pain 
because common people are not aware of healthy sitting posture they attain a sitting posture in which they feel relax which can further lead to body pains. In present study $97.67 \%$ bankers change their posture to relieve low back pain.

Females ached most frequently from the musculoskeletal disorders as compared to men. ${ }^{11,14,18}$ Present study stated that among banker's population males suffer more frequently from low back pain than female because in bank population of area selected for research there were more males $(68.9 \%)$ than females (31.1\%).

Bad job station design, continuous computer uses for the entire workday and repetitive computer work, such as data entry, have been associated with an increased risk of developing symptoms related to musculoskeletal disorders."

In industrialized countries musculoskeletal disorders are one of the most common causes of temporary work disability and the main cause of permanent work disability, accounting for high productivity loss." Sleep patterns were disturbed because of low back pain. About 52\% respondents cannot sleep because of pain. Results of present study showed that many daily life activities were disturbed because of low back pain such as standing up from the chair, bending or kneeling forward, putting up stockings, turning over the bed, walking more than 15 minutes and going up the stairs. About $45 \%$ respondents remain seated for a long time because of low back pain. According to this study $52.33 \%$ respondents ask help from others because of low back pain.

\section{CONCLUSION}

The prevalence of low back pain is high among bankers. Due to type of job the low back pain prevalence was found to be more among the men than women. It was found that due to low back pain bankers were not able to do daily life activities. The present study also found that many bankers remain seated for long time due and change their posture to relieve low back pain.

\section{LIMITATIONS}

This study is limited to Lahore city of Pakistan. We only found the prevalence among bankers. More researches are needed to investigate the strength of the muscle or level of weakness of muscles of low back.

\section{REFERENCES}

I. Bell JA, Burnett A. Exercise for the primary, secondary and tertiary prevention of low back pain in the workplace: a systematic review. J Occup Rehabil 2009 Mar;19(1):824. DOI: 10.1007/s10926-0099164-5.

2. Darwish MA, Al-Zuhair SZ. Musculoskeletal pain disorders among secondary school Saudi female teachers. Pain Res Treat 2013;2013:878570. DOI: $10 . \mid 155 / 2013 / 878570$.

3. Akkoc N. Are spondyloarthropathies as common as rheumatoid arthritis worldwide? A review. Curr Rhe um a tol Rep 2008 Oct; 10(5):371-8.

4. Koes B, Van Tulder MW, Thomas S. Diagnosis and treatment of low back pain. BMJ. $2006 \mathrm{Jun}$ |7;332(7555): |430-4.

5. Sharan D, Parijat P, Sasidharan AP, Ranganathan R, Mohandoss M, Jose J. Workstyle risk factors for work related musculoskeletal symptoms among computer professionals in India. J Occup Rehabil. 201I Dec; 2 I ( 4): 520 - 5. DOI: I0.1007/s 10926-0 | I-9294-4.

6. Rubin DI. Epidemiology and risk factors for spine pain. Neurol clin 2007;25(2):353-7I. DOI: I0.1016/j.ncl.2007.01.004

7. Moom RK, Sing LP, Moom N. Prevalence of musculoskeletal disorder among computer bank office employees in Punjab (India): a case study. Procedia Manuf 20।5;3:6624-3।.

8. Turhan N, Akat C, Akyüz M, Çakci A. Ergonomic risk factors for cumulative trauma disorders in VDU operators. Int J Occup Saf Ergon. 2008; I4(4):4I7-22. DOI: 10.1080/10803548.2008.| I 076782

9. Choobineh A, Nouri E, Arjmandzadeh A, Moh a madbaigi A. Musculoskeletal disorders among bank computer operators. Iran Occup Health. 2006;3(2):3-0.

10. Brandão AG, Horta BL, Tomasi E. Signs of musculoskeletal disorders in bank workers from the city of Pelotas and region: prevalence and associated factors. Rev Bras Epidemiol 2005;8(3):295-305.

I I. Akrouf Q, Crawford J, Al Shatti A, Kamel M. Musculoskeletal disorders among bank office workers in Kuwait. East Mediterr Health J 2010 Jan; I6(I):94-100.

12. Mohammadi G. Musculoskeletal symptoms among bank office workers: two years follow-up survey. J Musculoskelet Res 20|4; | 7(04): | 450018.

13. Abledu J, Abledu G. Multiple logistic regression analysis of predictors of musculoskeletal disorder and disability among bank workers in Kumasi, Ghana. J Ergonomics 20I2;2:III-5. DOI:10.4I72/2I657556.1000III

14. Fukui MI, Chiba K, Kawakami M, Kikuchi S, Konno S, Miyamoto M, et al. Japanese Orthopaedic Association Back Pain Evaluation Questionnaire. Part 2. Verification of its reliability: The Subcommittee on Low Back Pain and Cervical Myelopathy Evaluation of the Clinical Outcome Committee of the Japanese Orthopaedic Association. J Orthop Sci 2007 Nov; I 2(6):526-32. Epub 2007 Nov 30.

15. Das B, Ghosh T. Assessment of ergonomical and occupational health related problems among VDT workers of West Bengal, India. Asian J Med Sci 20 I 4; I (2):26-3 I.

16. Halvani G, Salmani Nodousgan Z. Survey of Musculoskeletal disorders among bank staff in Yazd. Occup 
Med J 20I I;3(1): I-7.

17.Sulaiman SK, Kamalanathan P, Ibrahim AA, Nuhu JM. Musculoskeletal disorders and associated disabilities among bank workers. Inter J Res Med Sci 2017;3(5): II53-8.

18. Maiya AG, Bhat VH, Sathiakumar N. Prevalence of Work-Related Wrist and Hand Musculoskeletal
Disorders (WMSD) among Computer Users, Karnataka State, India. J Clin Diagn Res $2011 ; 5(3): 605-7$.

\section{AUTHOR'S CONTRIBUTION}

Following authors have made substantial contributions to the manuscript as under:

ST: Concept \& study design, acquisition and analysis of data, drafting the manuscript, final approval of the version to be published

FA: Analysis \& interpretation of data, critical review, final approval of the version to be published

AA \& SAG: Drafting the manuscript, critical revision, final approval of the version to be published

Authors agree to be accountable for all aspects of the work in ensuring that questions related to the accuracy or integrity of any part of the work are appropriately investigated and resolved.

\section{CONFLICT OF INTEREST}

Authors declared no conflict of interest GRANT SUPPORT AND FINANCIAL DISCLOSURE NIL 